\title{
The problematic early Cambrian fossil Tumulduria incomperta represents the detached ventral interarea of a paterinid brachiopod
}

Christian B. Skovsted, Artem Kouchinsky, Stefan Bengtson, and Lars E. Holmer Acta Palaeontologica Polonica 59 (2), 2014: 359-365 doi: http://dx.doi.org/10.4202/app.2012.0084

The organophosphatic early Cambrian (Terreneuvian, Cambrian Stage 2) fossil Tumulduria incomperta has been problematic ever since its original description in 1969. Comparison of abundant specimens from the Lower Cambrian of Siberia with co-occurring brachiopod valves show that $T$. incomperta represents the central portion of the ventral interarea of a paterinid brachiopod similar to Cryptotreta neguertchenensis, and that the domed central portion of typical Tumulduria specimens represents the ridge-like pseudodeltidium of the interarea.

Key words: Brachiopoda, problematica, Tommotian Stage, Terreneuvian, Cambrian, Siberia.

Christian B. Skovsted [christian.skovsted@nrm.se], Department of

Palaeozoology, Swedish Museum of Natural History, Box 50007, SE-104 05

Stockholm, Sweden; Artem Kouchinsky [artem.kouchinsky@nrm.se] and

Stefan Bengtson [stefan.bengtson@nrm.se], Department of Palaeozoology and

Nordic Center for Earth Evolution, Swedish Museum of Natural History, Box

50007, SE-104 05 Stockholm, Sweden; Lars E. Holmer [lars.holmer@pal.uu.se], Department of Earth Sciences, Palaeobiology, Uppsala University, Villavägen 16, SE-752 36 Uppsala, Sweden.

This is an open-access article distributed under the terms of the Creative Commons Attribution License (for details please see creativecommons.org), which permits unrestricted use, distribution, and reproduction in any medium, provided the original author and source are credited. 
